\title{
Foreign Exchange Intervention and Exchange Rate Volatility in Peru
}

\author{
Alberto Humala* and Gabriel Rodríguez** \\ * Central Reserve Bank of Peru \\ ** Central Reserve Bank of Peru and Pontificia Universidad Católica del Perú
}

\author{
DT. N ${ }^{\circ} 2009-008$ \\ Serie de Documentos de Trabajo \\ Working Paper series \\ Abril 2009
}
Los puntos de vista expresados en este documento de trabajo corresponden a los autores y no reflejan necesariamente la posición del Banco Central de Reserva del Perú.

The views expressed in this paper are those of the authors and do not reflect necessarily the position of the Central Reserve Bank of Peru. 


\title{
Foreign Exchange Intervention and Exchange Rate Volatility in Peru*
}

\author{
Alberto Humala \\ Research Department, Central Reserve Bank of Peru \\ Gabriel Rodríguez ${ }^{\dagger}$ \\ Research Department, Central Reserve Bank of Peru \\ Pontificia Universidad Católica del Perú
}

This Version: March 05, 2009

\begin{abstract}
Flexible exchange rate experience in Peru has been accompanied by frequent official interventions in the form of foreign exchange purchases or sales. Monetary authority pursues reducing excess volatility in the exchange rate through its direct intervention. However, in recent years, this intervention has concentrated in US dollars purchases, apparently signaling a bias towards defending a given exchange rate level (not necessarily fixed). For the period 1994 - 2007, this document assesses consistency of the empirical evidence with the goal of reducing exchange rate volatility. Thus, it uses univariate and multivariate time series models subject to stochastic shifts to study currency pressures. Results suggest consistency with the reduced-volatility goal. Nonetheless, in line with other studies, factors such as the foreign exchange gap with respect to its trend also induce foreign exchange intervention.
\end{abstract}

JEL Classification: C22, C32, E52, F31.

Keywords: Foreign Exchange Intervention, Exchange Rate Volatility, Markov-Switching Models.

\footnotetext{
${ }^{*}$ We thank useful comments from participants to the XXV Meeting of Economists of the Central Bank of Peru in December 2007. We also thank Carlos Montoro for useful comments. The views expressed in this paper are those of the authors and do not reflect necessarily the position of the Central Bank of Peru.

${ }^{\dagger}$ Address for Correspondence: Gabriel Rodríguez, Banco Central de Reserva del Perú, Subgerencia de Investigación Económica, 441-445 Jr. Miroquesada, Lima 1, Lima, Peru. Telephone: +511-613-2000 (3970), Fax: +511-613-2516, E-Mail address: gabriel.rodriguez@bcrp.gob.pe.
} 


\section{Introduction}

Flexible exchange rate experience in Peru has been accompanied by frequent official interventions in the form of foreign exchange purchases or sales. Monetary authority pursues reducing excess volatility in the exchange rate through its direct intervention. Additionally, it accumulates international reserves to enhance the country's financial strength. However, in recent years, this intervention has concentrated in US dollars purchases, apparently signalling a bias towards defending a given exchange rate level (not necessarily fixed).

Exchange rate literature has discussed extensively on the purpose of official intervention, both sterilized and non-sterilised ${ }^{1}$ and has advanced many arguments in favour of (and against) it. $^{2}$ One argument supporting intervention is the adjustment criteria. On the basis of an (implicit or explicit) adjustment cost function, monetary authority perceives that the adjustment from short-run exchange rate values towards its long-term equilibrium path would be costly and potentially harmful to the domestic economy should it leave to market forces alone. In order to smooth the adjustment process and to induce a so-considered optimal pace towards equilibrium, the central bank needs to intervene the foreign exchange market. Moreover, according to a recent survey, reported on Neely (2006), monetary authorities firmly belief that their intervention help reducing market volatility and, therefore, ends up reaching efficiently its goal of smoothing the adjustment process.

The Peruvian official intervention relies on a somewhat different reduced-volatility argument. Due to a large degree of financial dollarization of the economy, excess volatility in the foreign exchange market could trigger balance sheet effects on an ample share of businesses, affecting aggregate supply-demand equilibrium that might misfire the inflation target. ${ }^{3}$ Therefore, what the central bank does is to prevent rapid variations, in both directions, in the exchange rate (without explicitly indicating what is considered excess volatility). ${ }^{4}$

This document evaluates whether empirical evidence for Peru is consistent with reducing excess exchange rate volatility through intervention or with some other explanatory variables. ${ }^{5}$ This paper studies the dynamics of the exchange rate and assesses empirically if intervention responds exclusively to exchange rate volatility factors (such as depreciation or appreciation pressures).

The paper is organized as follows. Section 2 describes the econometric approach, consider-

\footnotetext{
${ }^{1}$ Sterilised intervention leave the money market quantity balance undisturbed. Non-sterilised internvention would affect domestic monetary base.

${ }^{2}$ See Sarno and Taylor (2002) for an overview of such arguments.

${ }^{3}$ Carranza et al. (2003) find evidence that, for highly-dollarized firms in Peru, investments decisions are negatively affected by real depreciation of the domestic currency.

${ }^{4}$ For a discussion on fear of floating see Calvo and Reinhart (2000).

${ }^{5}$ Arena and Tuesta (1999) find that official intervention in Peru is efficient in reducing exchange rate volatility and that it could actually influence the level of nominal exchange rate.
} 
ing univariate and multivariate models subject to regimen switching. The next section presents the stylized facts for the sample under study and reports on the empirical evidence about the relationships among a set of variables representing currency pressures and the link between net purchase by the central bank and exchange rate volatility. This section presents also an analysis on the determinants of the exchange rate intervention. Section 4 concludes and sets a research agenda.

\section{Econometric approach}

The direction foreign exchange intervention takes (purchase or sale) and the practical terms under which it is conducted (frequency, amount, volatility, persistence, etc.) should be consistent with the central bank pursuing a reduction in exchange rate uncertainty. Although the monetary authority does not explicitly define what excess volatility means, analysis of the exchange rate dynamics and volatility should reveal any feasible market relationship between exchange rate volatility and central bank's intervention. Primarily, then, univariate models are used to evaluate the stochastic behavior of exchange rate and intervention amounts. Considering that currency pressures could prompt changes in interest rate spread (between domestic and foreign currency interest rates) and in international reserve accumulation (measured as the central bank's net international position), these variables are also study independently. Since empirical evidence suggest high variance in the dynamics of these variables, their modeling considers the feasibility of regime shifting in the autoregressive stochastic representation. ${ }^{6}$

Thereafter, vector autoregressions models (VAR methodology), subject to Markov switching (MS), are estimated to assess currency pressures (depreciation or appreciation) through changes in the exchange rate, interest rate spreads, and international reserves. ${ }^{7}$ A similar MSVAR approach is taken to model directly the relationship between exchange rate variations and official intervention.

A number of other econometric approaches are in use in the empirical literature to evaluate exchange rate interventions. ${ }^{8}$ In particular, variants of GARCH modeling are used to account for time-varying volatility in foreign exchange markets. See, for instance, Beine, BénassyQuéré, and Lecourt (1999) for a study on the impact of exchange rate intervention on the short run dynamics of the Deutschemark and the yen against the US dollar (with a FIGARCH model); Hillebrand and Schnabl (2003) for Japan (with a GARCH approach); and more recent

\footnotetext{
${ }^{6}$ Empirical literature attributes frequently a regime switching stochastic behaviour to exchange rates. For a recent discussion about these exchange rate nonlinearities, see Sarno (2005).

${ }^{7}$ Net international position from the central bank is considered here as a proxy of reserve variations. Alternatively, available intervention data could be directly used.

${ }^{8}$ Event studies are not directly used here, since the frequency at which intervention in Peru takes place makes it difficult to isolate the effects of any single intervention day or episode. See, for example, Fatum and Hutchison (2003) for an application to daily US official intervention operations.
} 
applications from Kamil (2008) for the case of Colombia (a two-stage instrumental variable model that allows for GARCH effects in the conditional variance) ${ }^{9}$ and Hoshikawa (2008), again for Japan (with GARCH modeling). Alternatively, conditioning distribution moments on regime switching are found, for example, in applications by Aloy, Girardin, and Protopopescu (2001); Beine, Laurent, and Lecourt (2003); and Taylor (2004). ${ }^{10}$ Furthermore, attempts to introduce varying volatility inside each regime can be found in Brunetti, Mariano, Scotty, and Tan (2003) and Haas, Mittnik, and Paolella (2004) with applications of Markov switching GARCH models to explain currency crises and exchange rate dynamics, respectively.

\section{$2.1 \quad$ Univariate models}

Various $M$-regimes autoregressive models assess independently the data generating processes of exchange rate variations, central bank's net purchases, changes in central bank's net international position, and variations in interest rates spreads. The general autoregressive representation takes the following form:

$$
y_{t}=\alpha\left(s_{t}\right)+\sum_{j=1}^{p} \beta_{j}\left(s_{t}\right) y_{t-j}+\epsilon_{t}
$$

where $y_{t}$ is the studied variable, $s_{t} \in\{1, \ldots, M\}$ is a discrete-value non-observable state variable, and $\epsilon_{t} \sim \operatorname{NID}\left(0, \sigma^{2}\left(s_{t}\right)\right)$ is the error term. It is assumed that $s_{t}$ follows a Markov chain that varies among $M$ regimes and it is defined by the transition probabilities $p_{i j}=\operatorname{Pr}\left(s_{t+1}=j \mid s_{t}=\right.$ $i)$ and $\sum_{j=1}^{M} p_{i j}=1 \quad \forall i, j \in\{1, \ldots, M\}$. Following Krolzig (1997), this model specification is denoted as $\operatorname{MS}(M)-\operatorname{AR}(p) .{ }^{11}$ Such as approach should allow capturing shifts in mean, variance and persistence.

\subsection{Multivariate models}

Considering that feasible nonlinearities in each relevant variable might induce regime switching behavior on the relationships among those variables, the following VAR is specified subject to

\footnotetext{
${ }^{9}$ Which presents a similar study case than Peru. Appreciation pressures on the domestic currency due to recent macroeconomic performance and international trends, has prompted the central bank to intervene largely in the foreign exchange market, risking consistency with the inflation targeting regime in place.

${ }^{10}$ Alternatively, regime switching modeling through a time-varying smooth transition autoregressive (TVSTAR) model is found in Sollis (2008).

${ }^{11}$ Recent applications include also the possibility of conditional heteroskedasticity (MS-GARCH) and exogenous variables (MS-ARX).
} 
regime shifting:

$$
Y_{t}=v\left(s_{t}\right)+\sum_{j=1}^{p} A_{j}\left(s_{t}\right) y_{t-j}+\epsilon_{t}
$$

where $Y_{t}$ represents alternatively two set of endogenous variables. One set is made up of exchange rate, central bank's net international position, and interest rate spreads (all in variations) and are to signal pressures on the domestic currency ${ }^{12}$. The second variable set includes exchange rate variations and intervention amounts and aim at modeling directly the relationship between exchange rate volatility and official intervention. Once again, $s_{t}$ is a discrete-value, non-observable state variable with multiple regimes and $\epsilon_{t} \sim N I D\left(0, \Sigma\left(s_{t}\right)\right)$. All model parameters, in matrices $v$ and $A$ and the variance-covariance matrix, are regime-dependent. This is a generalization of the standard VAR representation and it is denoted as $\operatorname{MS}(M)-\operatorname{VAR}(p) .{ }^{13}$

\section{Empirical evidence}

Data frequency is taken, in turn, daily, weekly, and monthly for the exchange rate (average bid-ask). Sample sizes vary according to data availability. Interest rate spreads are measured as the difference between the domestic-currency interbank rate and the foreign-currency interbank rate (both in annual percentages). The central bank's net international position is an end-of-period stock variable and its level is represented in US\$ millions, while its changes in percentages. Intervention is measured as US\$ millions of net purchases, purchases or sales of foreign currency by the domestic central bank.

\subsection{Stylized facts}

There exists evidence of two clearly differentiated regimes in exchange rate variations over the sample 1994-2007: periods of high volatility alternate with periods of market stability. Higher volatility periods are mainly associated to the financial crises during the 1990s: Mexico (1994:8 to 1995:3), South East Asia, Brazil, and Russia (1997:10 to 2000:5) and to certain domestic political and financial unrest episodes in the 2000s (i.e., the period 2005:9 to 2006:5 of presidential elections uncertainty).

In turn, central bank's intervention seems to be subject to two switching regimes associated intervention levels. In this case, however, the sequence of regime transitions resembles more that of a structural break. The first regime spans basically the period up to November 2003,

\footnotetext{
${ }^{12}$ See Martínez (2002) for a similar Markov Switching VAR, with the addition of shifts in regime bein endogenously determined (through time varying transition probabilities). More recently, Arias and Erlandsson (2005) present a variation of this modeling for an early warning system for financial crises including a similar variable set.

${ }^{13}$ This representation could be extended to include exogenous variables and time-varying transition probabilities.
} 
with both purchases and sales taking place. From 2004 onwards, the second regime shows almost exclusively purchases at a much larger scale, both in number of times and in intervention amounts. This second intervention pattern could suggest that the central bank is defending a particular exchange rate level rather than smoothing its volatility. Alternatively, this pattern could be the result of the exchange rate switching behavior inducing deeper intervention for stronger depreciation or appreciation pressures, which would be consistent with the goal of reducing excess volatility.

For the central bank's net international position, the non-linear autoregressive approach suggests a similar regime switching pattern than for the exchange rate variations (but with less high-volatility episodes in the 2000s). The South East Asian crisis, the exchange rate turmoil by the end of 2000, and the unsettle conditions by the end of 2006 and beginning of 2007 are all considered in the high-volatility regime.

Finally, in the case of the interest rate spread, results show an important break in regimes that coincides clearly with the adoption of the inflation targeting scheme of monetary policy in 2002. Interest rate spread volatility is reduced substantially thereafter.

\subsection{Exchange rate pressures}

A MS(2)-VAR(1) model of exchange rate, central bank's net international position, and interest rate spread (all in changes) is estimated, for the sample 1994-2007, to assess currency pressures. ${ }^{14}$ Relationships among these variables seem to be overshadowed by the regime shift in the interest rate spread. ${ }^{15}$ Despite conveniently applying a Markov switching model when the stochastic behavior of variables suggest regime shifting patterns, the break in interest rate spreads (that accompanied the adoption of inflation targeting) dominate over all other regime shifts in these variables' relationships. Increasing the VAR's number of regimes does not solve the problem.

Therefore, in order to assess feasible regime shifts in exchange rate pressures, the MS(2)$\operatorname{VAR}(1)$ is estimated for a shorter sample that excludes the change in monetary policy (19932003). In this case, there is a clear alternate sequence of low and high volatility episodes of currency pressures, shown by exchange rate variations, central bank's net international position, or interest rate spreads. ${ }^{16}$ The period of higher volatility is mainly associated to the international financial crises and to domestic financial uncertain episodes.

\footnotetext{
${ }^{14}$ To be more precise, a MSIH(2)-VAR(1) model is estimated, where I and H stand for the intercept and the variance (heteroskedasticity) being conditionals to the regime.

${ }^{15}$ See Figure 1 for the smoothed probabilities in each data observation.

${ }^{16}$ See Figure 2 with the regime smoothed probabilities.
} 


\subsection{Official intervention and exchange rate volatility}

Considering the entire sample, two regimes are clearly identified in the relationship between net purchases and exchange rate volatility (see Figure 3). Crucially, regime switching behavior in net purchases seems to induce nonlinearity in these variables' relationship (and not that in exchange rate variations). Estimation of a $\operatorname{MS}(2)-\operatorname{VAR}(1)$ indicates, in the equation for net purchases, an average almost ten times smaller and an error variance six times smaller in the regime that spans up to 2003 than in the regime that goes from 2004 onwards (with a higher volume and frequency of interventions). Even though contemporaneous correlation between variables is clearly negative in both regimes, it reduces substantially in the more volatile regime (contrary to expectations). The relationship between net purchase and exchange rate volatility lags is also significantly negative.

In order to assess this relationship before the important change in net purchases, from 2004 onwards, the MS(2)-VAR(1) is also estimated for the sample 1994-2003. In this case, negative contemporaneous and lag correlation between net purchases and exchange volatility are confirmed and so is the presence of regime switches. Actually, the regime switching pattern is similar to that of the exchange rate, although regimes alternate more frequently in this case (see Figure 4). The average net purchase is still eight times smaller in the low volatility regime (but with substantially lower levels than when the entire sample is considered) and the variance is three times smaller (again, smaller than under the entire sample estimation). Another important difference is that negative contemporaneous correlation becomes stronger in the high volatility regime, probably signalling greater efficiency of intervention with more uncertainty.

\section{Conclusions}

Empirical evidence suggests that official intervention in the foreign exchange market in Peru is consistent with the goal of reducing excess volatility in the foreign exchange rate. However, some other determinants are not discarded based on this evidence. In particular, the distance of the exchange rate from its trend (associated to the exchange rate level) would motivate larger official intervention. Meanwhile, changes in the interest rate spread seem to encourage this intervention (enlarges with the spread). However, evidence is mixed with respect to this spread, since this variable is non-significant statistically under the entire sample, but significant if considering the sample after the monetary policy change.

These results are a first econometric approximation to the analysis of official intervention in Peru. Research agenda includes assessing whether or not intervention is effective in reducing excess volatility in the foreign exchange market and whether or not it is consistent with the current inflation targeting scheme. 


\section{References}

Aloy, M., .E. Girardin, and C. Protopopescu (2001), "Central bank intervention and exchange rate dynamics with a regime switching VAR", First draft, September. Available on: http://www.ceders.org/docman/task,doc_download/gid,37/mode,view/

Arena, Marco and Pedro Tuesta (1999), "El objetivo de la intervención del banco central: ¿el nivel del tipo de cambio, la reducción de la volatilidad cambiaria o ambos?: un análisis de la experiencia peruana 1991-1998", Banco Central de Reserva del Perú, Revista de Estudios Económicos 5.

Arias, Guillaume and Ulf G. Erlandsson (2005), "Improving early warning systems with Markov switching model-an application to South-East Asian crises", March. Available on: http://www.cass.city.ac.uk/emg/seminars/Papers/Arias_Erlandsson.pdf

Beine, Michel; Agnès Bénassy-Quéré; and Christelle Lecourt (1999), "The impact of foreign exchange intervention: new evidence from FIGARCH estimations", CEPII, Document de travail 99-14.

Beine, Michel; Sébastien Laurent; and Christelle Lecourt (2003), "Official central bank interventions and exchange rate volatility: evidence from a regime switching analysis", European Economic Review 47, 891-911.

Brunetti, Celso; Roberto S. Mariano, Chiara Scotti, and Augustine H. H. Tan (2003), "Markov switching Garch models of currency crises in Southeast Asia", Penn Institute for Economic Research, PIER Working Paper 03-008.

Calvo, Guillermo A. and Carmen M. Reinhart (2000), "Fear of floating", National Bureau of Economic Research, Working Paper 7993.

Carranza, Luis J., Juan M. Cayo, José E. Galdón-Sánchez (2003), "Exchange rate volatility and economic performance in Peru: a firm level analysis", Emerging Markets Review 4, 472-496.

Fatum, Rasmus and Michael Hutchison (2003), "Is sterilized foreign exchange intervention effective after all? An event study approach", Economic Journal 113(487), 390-411.

Haas, Markus; Stefan Mittnik; and Marc S. Paolella (2004), "A new approach to Markovswitching GARCH models", Journal of Financial Econometricsl 2(4), 493-530.

Hillebrand, Eric and Gunther Schnabl (2003), "The effects of Japanese foreign exchange intervention: GARCH estimation and change point detection", Japan Bank for International Cooperation (JBIC), Discussion Paper 6. 
Hoshikawa, Takeshi (2008), The effect of intervention frequency on the foreign exchange market: the Japanese experience", Journal of International Money and Finance, doi: 10.1016/j.jimonfin.2008.01.004.

Kamil, Herman (2008), "Is central bank intervention effective under inflation targeting regimes? The case of Colombia", International Monetary Fund Working Paper WP/08/08.

Krolzig, Hans-Martin (1997), Markov-switching vector autoregressions. Modelling, statistical inference, and application to business cycle analysis, Lecture notes in economics and mathematical systems, Springer.

Martínez Peria, María Soledad (2002), "A regime-switching approach to the study of speculative attacks: a focus on EMS crises," Empirical Economics 27, 299-334.

Neely, Christopher J. (2006), "Central bank authorities' beliefs about foreign exchange intervention," Federal Reserve Bank of St. Louis, Working Paper 2006-045C.

Sarno, Lucio (2005), Towards a solution to the puzzles in exchange rate economics: where do we stand?, Finance Group, Warwick Business School, University of Warwick. February.

Sarno, Lucio and Mark P. Taylor (2002), The economics of exchange rates, Cambridge University Press. Cambridge, United Kingdom.

Sollis, Robert (2008), U.S. "Dollar real exchange rates: nonlinearity revisited", Journal of International Money and Finance, doi: 10.1016/j.jimonfin.2008.02.001.

Taylor, Mark P. (2004), "Is official exchange rate intervention effective?", Economica 71, 1-11. 


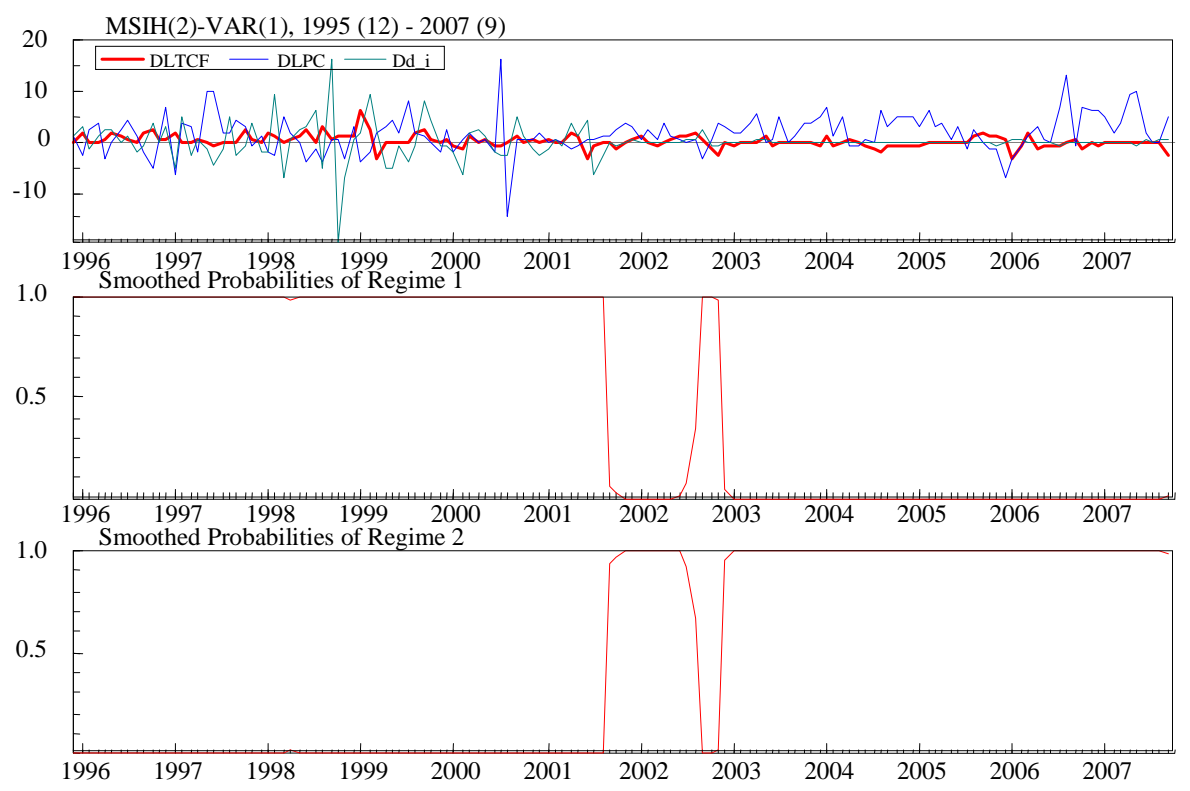

Figure 1: Exchange rate, net international position, and interest rate diferential

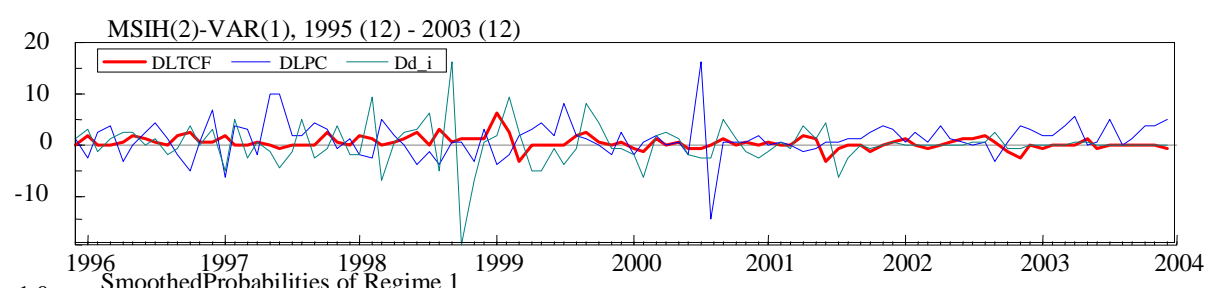

1.0
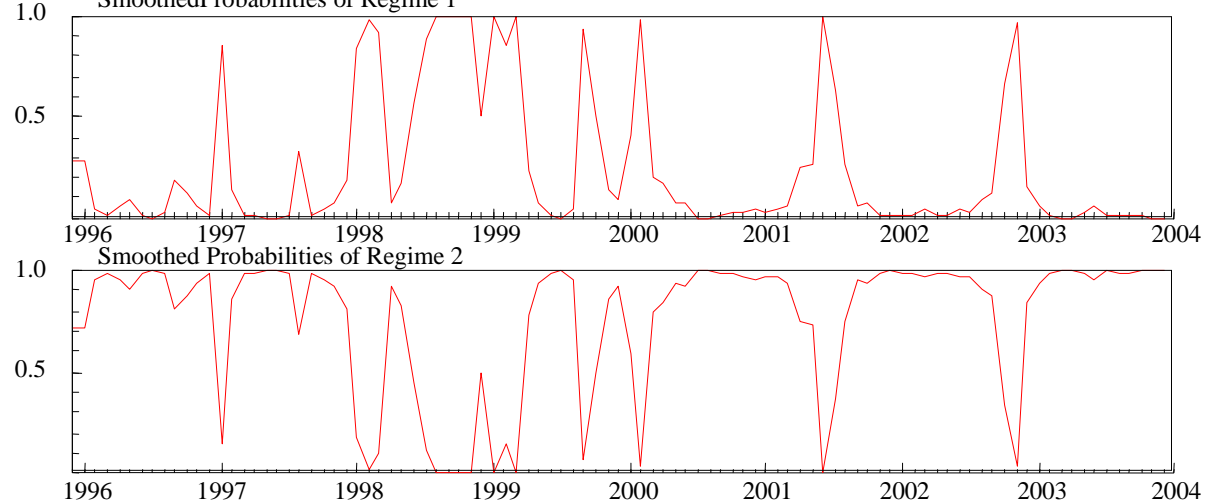

Figure 2: Exchange rate, net international position, and interest rate diferential 

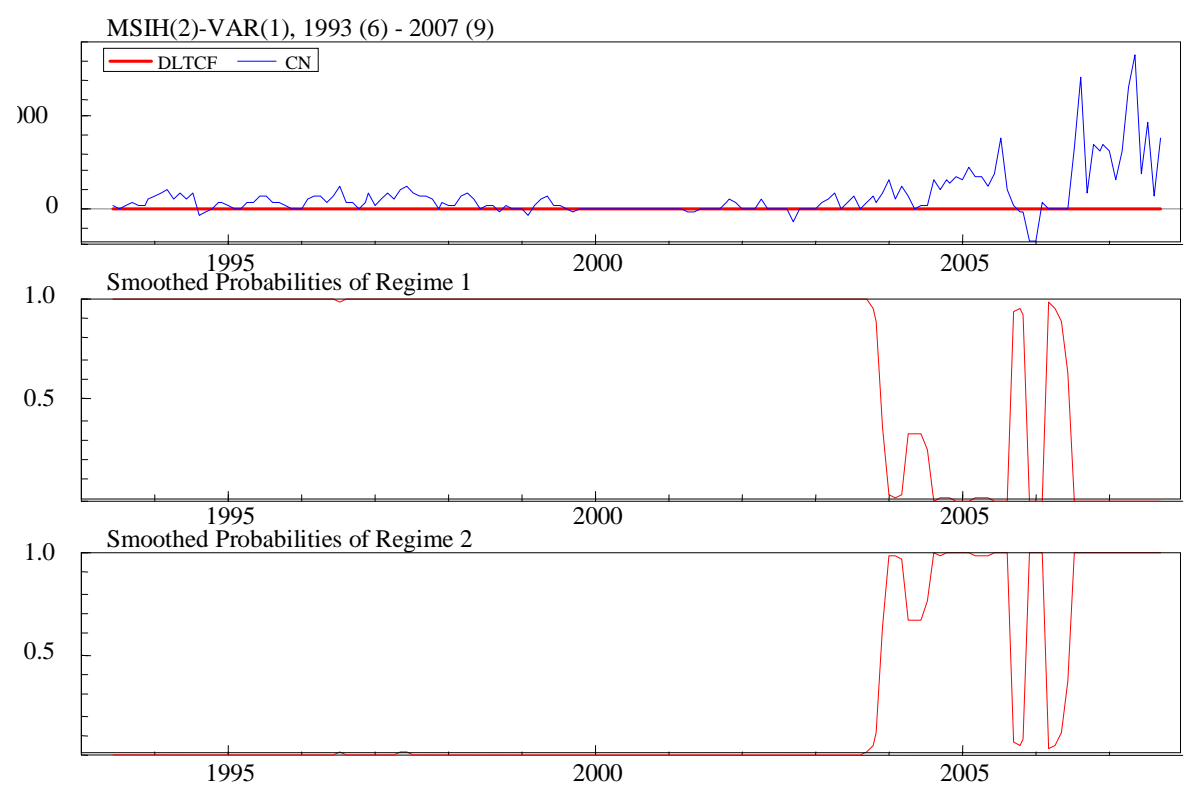

Figure 3: Exchange rate and official intervention

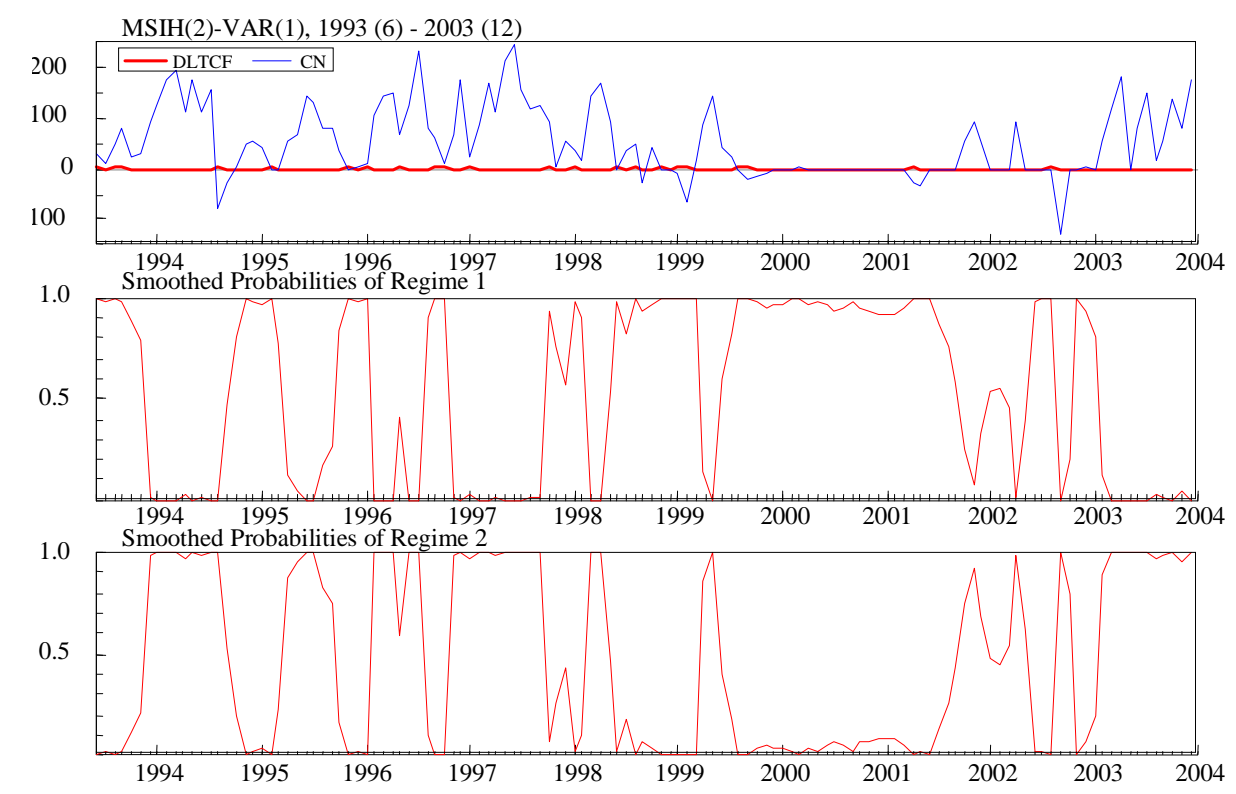

Figure 4: Exchange rate and official intervention 